\title{
The Emergence of a First Paradigm in Vocabulary Research: The Bibliometrics of System
}

\author{
Paul Meara \\ Swansea University \\ p.m.meara@gmail.com
}

\begin{abstract}
This paper uses a bibliometric method to analyse the vocabulary research published in the journal System between 1976 and 2017. The bibliometric method used here is co-citation analysis, an approach which allows us to map the influences that have significantly impacted on vocabulary research. The analysis is intended to expand on an earlier analysis by Lei and Liu (2019), which studied the outputs in System but also analyses the features of all the papers published in the journal. This paper identifies five main clusters in the System data set. It also reports how these clusters grow and change over time. It argues that the data point to the emergence of a first paradigm in vocabulary research (Kuhn, 1971), and suggests some ways in which this paradigm might shift in response to demographic changes among the researchers who publish in System.
\end{abstract}

\section{Introduction}

This paper is part of a series of studies that use bibliometric methods to examine the way L2 vocabulary research has developed over the last 50 years. Previous papers in this series (Meara, 2015, 2016, 2017, 2018) have focussed on the research output in successive years in the early part of the 1980s. One paper (Meara, 2014) tried to take a longer term view of the development of vocabulary research over most of the 20th century by applying bibliometric methods to the vocabulary research published in a single, long-lived journal, The Modern Language Journal $(M L J)$. MLJ has been a good source for bibliometric analysis since the first piece of vocabulary research published in the journal appeared as early as 1918 (Bagster-Collins, 1918). Papers reporting on vocabulary research have appeared frequently, but irregularly, in the journal from that date until the present day. $M L J$ is unusual in this respect, however. Most of the current journals have nothing like the longevity of $M L J$, and their coverage of the vocabulary research is correspondingly limited.

This does not mean that the other later-day journals do not offer us anything about vocabulary research. One journal, which is of particular interest, is System, first published in 1973, and described by Lei and Liu (2019) as "a major international journal in applied linguistics" (p. 1). Among the more recently published 
journals, System is interesting because it had a single editor for many years (Norman Davies seems to have managed the journal pretty much single-handedly from 1973 until 2010), and this gave the journal a consistent editorial policy during this time. Also, System had an eye to recent developments in educational technology, which meant that it published papers that were rather different from the research that was being published in other, more traditional outlets. An unusually large number of vocabulary research papers appeared in System, beginning in 1976, and some of these went on to become particularly influential and widely cited resources. I was able to identify 115 papers with a focus on vocabulary published in the journal between 1976 and 2017, and Figure 1 shows the distribution of the publication dates of these papers. A complete list can be found in Appendix 1. A total of 183 authors contributed to this data set. Paul Nation contributed to five papers; Norbert Schmitt contributed to four papers; Paul Meara contributed to three papers. A further 11 authors contributed to two papers (Agustín Llach, Akbarian, Alavi, Boers, Cobb, Hamada, Higginbotham, Leffa, Lindstromberg, Nassaji and Tian). The remaining 169 authors contributed to just one paper each.

There are two main points to note about the data set. Firstly, the distribution of the papers suggests that the vocabulary research reported in System seems to fall into three main phases: an initial phase covering the period 1974-1992, when relatively small numbers of papers were published - usually one or two in each year; a consolidation phase covering the period 1993-2012, when the number of papers published was slightly higher but only once reached as many as five papers in a single year; and an "inflation" phase, beginning in 2013, when the number of relevant publications expanded rapidly to eight or more publications per year. It is difficult to tell from these raw numbers whether the recent rapid increase in publications represents a genuine increase in the importance of vocabulary research, or whether it is just a reflection of the general increase in research output or a change in the editorial policy. The second point to note is that the pattern of authorships

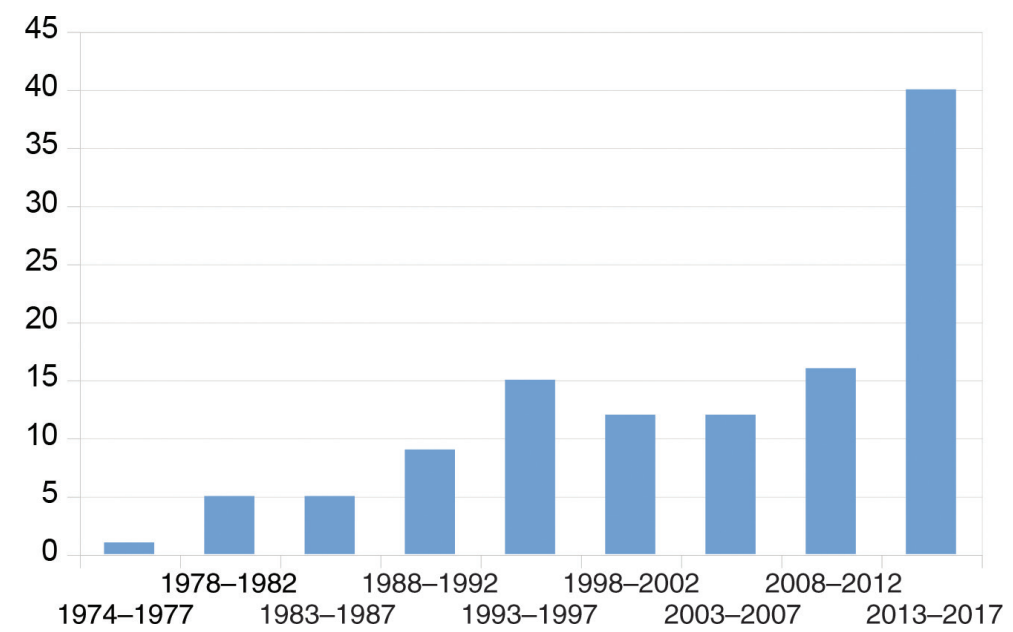

Figure 1. Papers published in System that deal with vocabulary acquisition, showing date of publication.

Source: VARGA database (Meara, n.d.). Last updated on 28.07.19. 
in this data set is peculiarly flat - a feature which I have drawn attention to in my earlier bibliometric analyses of the vocabulary research. Lotka (1926) pointed out that in large bodies of research, there is usually a relationship between the number of authors contributing a single paper to the data set, and the number of authors contributing to two, three, four and more papers. This relationship is sometimes referred to as Lotka's Law, although the relationship is a bit more flexible than this term implies. Lotka noted that the relationship normally reflected a power law function, where the number of authors we would expect to make $\mathrm{N}$ contributions to a data set can be described with a function, something like eq. 1:

eq $1 \quad M=S / N^{x}$

where $\mathrm{S}$ is the number of authors making a single contribution to the data set.

$\mathrm{N}$ is the number of contributions made by an author.

$\mathrm{M}$ is the expected number of authors making $\mathrm{N}$ contributions to the data set.

The exponent (x) varies from one discipline to another but is normally close to 2 .

Table 1 summarises the data from System.

It will be immediately obvious that the data set published in System has a strikingly large number of authors who contribute to a single paper, and a relatively small number of people publishing a substantial body of work in this journal. Given that 168 authors contributed to only one paper, we might expect as many as 42 authors to be contributing to two papers, 19 authors contributing to three papers, 10 authors contributing to four papers and 7 authors contributing to five papers. We might even expect to find five authors contributing to six papers, three authors contributing to seven papers and two contributing to eight papers. The actual figures in the System data set fall far short of these expectations: $98 \%$ of the authors in the data set contributed to only one or two papers. The figures suggest that for vocabulary research in this journal, the value of the exponent in equation 1 is about 3.93 - a figure which is unusually high, but broadly in line with previous reports for vocabulary research.

Obviously, most readers of Vocabulary Learning and Instruction will not be surprised to find that Nation, Schmitt and Meara figure in the list of authors of multiple papers, although they might be surprised to note that some other well-known figures in the field (e.g., Laufer, Hulstijn and Read) do not. (Laufer, for instance, contributed to just one paper, while Hulstijn and Read did not contribute at all.) Equally, some readers will be surprised that some of the authors contributing two papers in this data set will not be well known to the research community. Clearly, simply counting the number of papers in the data

Table 1: Authors contributing N papers in the System data set (1974-2017)

\begin{tabular}{lcccccccc}
\hline No. of papers & 1 & 2 & 3 & 4 & 5 & 6 & 7 & 8 \\
\hline Lotka expected & 168 & 42 & 19 & 10 & 7 & 5 & 3 & 2 \\
System actual & 168 & 11 & 1 & 1 & 1 & & & \\
\hline
\end{tabular}


set that each author contributes to does not tell us a great deal about the kind of ideas that are circulating among vocabulary researchers. In order to examine this idea, we need to dig behind the raw statistics of publication.

For this reason, the main approach used in this paper consists of a co-citation analysis of the data set. Co-citation analysis was first developed by Small (1973) and White and Griffith (1981), both building on earlier work by de Solla Price (1965). The method is widely used in bibliometric analyses of small research fields. The approach takes as its raw input the citations that are listed at the end of a typical research paper. The approach identifies instances of sources who tend to be cited together, and from these cases of co-occurrence, it constructs clusters of sources who seem to represent particularly strong influences in the research. Co-citation analysis assumes that sources that are frequently cited together in many papers in a data set are particularly influential (Price refers to them as Invisible Colleges. de Solla Price \& Beaver, 1966). So, for example, if Haastrup, Jensen and Jespersen frequently appear together in the citation lists of the papers in a data set, then we might want to argue that they jointly form an important influence in the research, even if the data set being analysed does not include a paper authored by any of them, and even though all three authors may never have worked together. And if a number of other authors are also cited alongside Haastrup, Jensen and Jespersen, a co-citation analysis would identify them as a cluster of related sources.

\section{Analysis 1: The overview}

In a typical co-citation analysis, the following steps are carried out:

Firstly, we make a list of all the authors cited in all of the papers in the data set, and list them by frequency. In the System data set, 2,728 different sources are cited, an average of 24 per paper. Most of these sources are cited only once, but many sources are cited much more frequently. The most cited authors in this data set are Nation (cited in 78 papers), Laufer (cited in 55 papers), Meara (cited in 48 papers), Schmitt (cited in 47 papers), Hulstijn (cited in 27 papers), Read (cited in 26 papers), Cobb (cited in 21 papers) and Coxhead (cited in 20 papers). All of these sources will be familiar to the readers of Vocabulary Learning and Instruction, and are easily recognisable as Significant Influences in L2 vocabulary research. The distribution of the remaining sources is shown in Table 2.

Seventy-five per cent of the sources are cited in only one paper. These sources seem to be important for only one author, and there is clearly no case for regarding them as sources who strongly influence the field. Other sources, who are cited more frequently, seem to be more important, and in the second step of the co-citation analysis, we identify the sources that are cited the most often in the data set. Conventionally, we look for an inclusion threshold, which gives us about 100 most-cited sources. In this data set, the closest we can get to the

Table 2: The number of sources cited $\mathrm{N}$ times in the System data set.

\begin{tabular}{lcccccccccccccccccc}
\hline $\mathrm{N}$ & 18 & 17 & 16 & 15 & 14 & 13 & 12 & 11 & 10 & 9 & 8 & 7 & 6 & 5 & 4 & 3 & 2 & 1 \\
\hline Cases & 1 & 2 & 0 & 4 & 2 & 4 & 2 & 2 & 9 & 5 & 11 & 15 & 32 & 34 & 64 & 132 & 351 & 2050 \\
\hline
\end{tabular}


conventional figure comes from selecting the 96 sources who are cited at least six times in the data set. Setting the inclusion threshold at six citations is basically an arbitrary choice, which excludes a large number of sources who fail to meet it. We will return to this point later in the paper.

In the third step of the co-citation analysis, we examine the citation lists at the end of each paper, and identify cases where two of the 96 sources derived from Step 2 are cited alongside each other. These occurrences are marked on a large matrix. This process is arduous and error-prone, so we normally automate it. The amount of additional data generated by this process is huge: a paper that cites 10 sources will generate $10 * 9 / 2=45$ co-citations, a paper that cites 50 sources will generate $50 * 49 / 2=1,225$ co-citations, while a paper that cites 100 sources will generate $100 * 99 / 2=4,950$ co-citations. With over 100 papers in the System data set, many of which have extensive reference lists, it will be immediately obvious that the process of collecting the co-citations generates far more data than we can conveniently handle manually.

Fortunately, using a computer makes it a relatively straightforward job to isolate the co-citations that we are interested in for the fourth step of the co-citation analysis. For this step, we identify any co-citation that involves two of the 96 sources that we listed in Step 2, and count the number of times this co-citation occurs in the data set. We can identify a total of 2,614 co-citation pairs in the System data set, but the strength of these links varies considerably. Laufer and Nation, the strongest co-citation link, appears 48 times in the list, indicating that these two authors are co-cited in $42 \%$ of the papers in this data set. At the other extreme, 1,132 of the co-citations appear just once: it is conventional in a co-citation analysis to ignore weaker links of this sort.

In Step 5, we submit these data to a mapping program, which allows us to visualise the connections between the 96 sources as a connected network. Figure 2 shows a network of this sort, which was generated using the Gephi program (Bastian, Heymann, \& Jacomy, 2009). In this map, the size of the nodes reflects the betweenness centrality of the nodes: this is a measure, which reflects the importance of a node in the network. A node with a high betweenness centrality score connects many disparate parts of the network, while a node with a low betweenness centrality score will have a small number of links limited to a restricted part of the network. Figure 2 also shows the strength of the co-citation connections between the sources (the thickness of the linking edges). These strengths vary a lot: Laufer and Nation, as already noted are cited together in 48 papers. Weaker links (links that occur fewer than four times in the data set) have been omitted from Figure 2 in the interests of simplicity. This simplification results in one very large component in the network, and one singleton (Paivio) who is no longer part of the connected network.

It is immediately obvious that four sources dominate the network: Nation, Laufer, Schmitt and Meara. Nation, of course, is the pre-eminent source, co-cited alongside almost every other source in the map. Put simply, if we choose two random sources in this map, let us call them $\mathrm{X}$ and $\mathrm{Y}$, then we can always find a short path from $\mathrm{X}$ to $\mathrm{Y}$ via Nation, even if there is no direct path between them. Laufer is only slightly less central than Nation - there are a few nodes that do not 


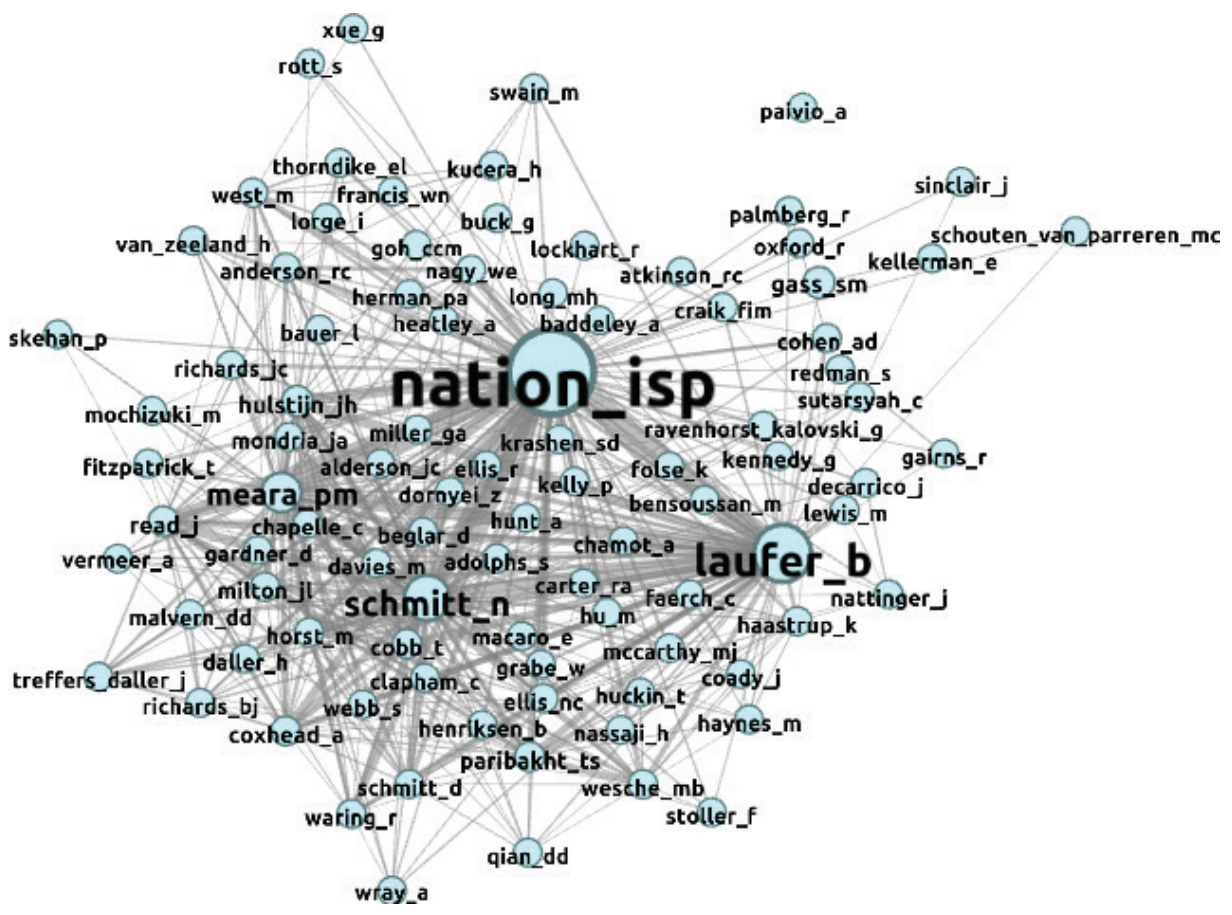

Figure 2. A co-citation analysis of the vocabulary research in System 1974-2017: N = 96. Threshold for inclusion: Six citations, edge strength $>3$.

have direct co-citation links with her. Schmitt and Meara are somewhat less central to the network than Nation and Laufer, but still much more central than any of the remaining sources. Ironically, the dominance of Nation and Laufer means that their influence runs right across the map but does not actually contribute much to the overall structure of the network: being co-cited with Nation or Laufer is a characteristic of every source, and this feature does not discriminate between them. This means that we can greatly simplify the map of the System data by eliminating Nation, Laufer, Schmitt and Meara from our analysis, and a map that does this is shown in Figure 3.

This map is straightforward and relatively easy to interpret. Eliminating the core sources from this map has left us with 11 detached sources that were mainly associated with the central core: their co-citations with the remaining sources are not strong enough for them to appear in the map.

de Groot is the sole representative of a large body of research concerned with lexical representation in bilinguals. This work tends to be laboratory based and very technical, and it has only a limited impact on the vocabulary research published in System.

Miller, Baddeley and Paivio are psychologists who have influenced L2 vocabulary research: Miller is most often cited for his work on short-term memory (Miller, 1956); Paivio is mostly cited for his work on the Dual Coding 


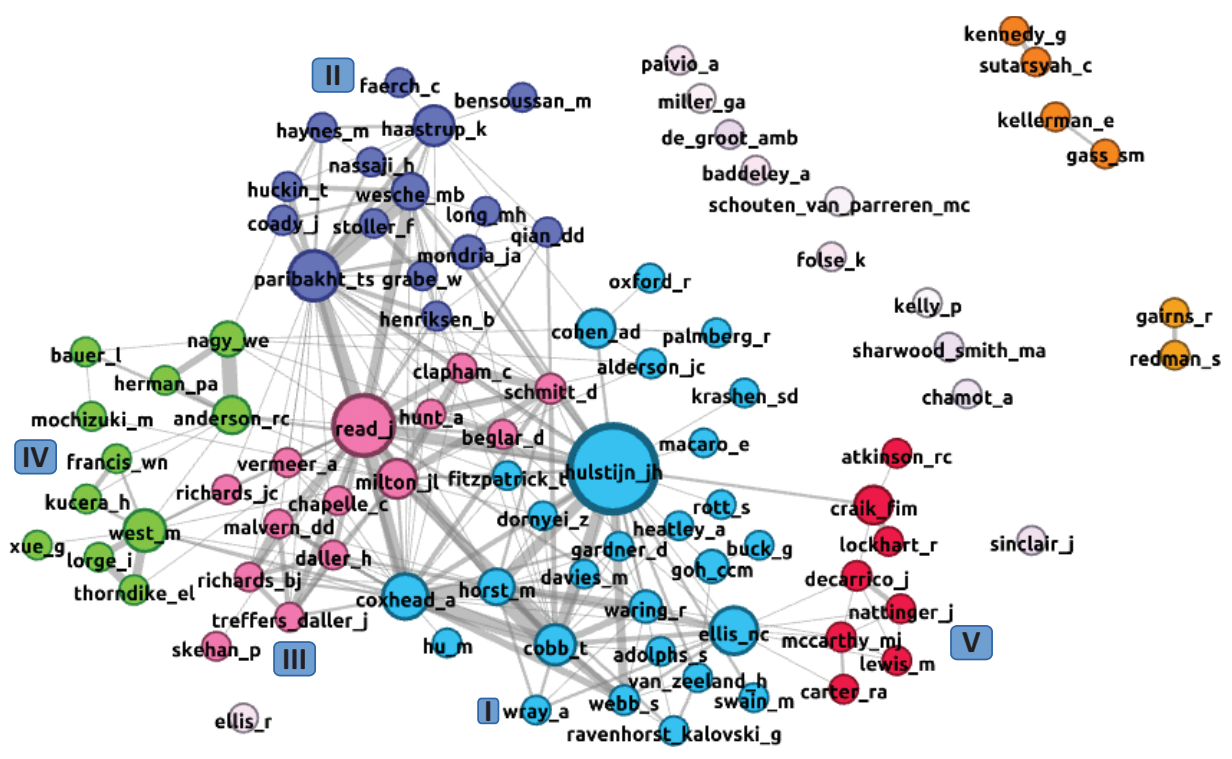

Figure 3. A co-citation map of the System data set.

Data: 115 papers published between 1974 and 2017. Ninety-three source nodes. Threshold for inclusion: six-plus citations; links appearing less than four times excluded. Excluded core nodes: Nation, Laufer, Schmitt and Meara.

Theory (e.g., Paivio, 1971); Baddeley is the main theorist of working memory (e.g., Baddeley \& Hitch, 1974). Taken together, these three sources look like a group of classical sources that once influenced work on memory and L2 vocabulary acquisition. In this dataset, they are not sufficiently strong to form an identifiable cluster, and this perhaps suggests that their importance as Influences is on the wane.

Chamot is principally concerned with learning strategies. In this data set, she is principally cited in papers that deal with learners' strategies for dealing with unknown words, particularly in listening comprehension.

Kelly's work deals with long-term retention of vocabulary. In this data set, he too is mainly cited in papers that deal with listening comprehension.

Folse is best known for his 2004 book Vocabulary Myths. In this data set, he is mainly cited in experimental studies that examine the way learners acquire vocabulary in intentional as opposed to implicit learning situations.

$R$ Ellis published two papers in System (1997 and 2017) and is cited in nine papers in the data set, so it is a bit surprising to note that he does not find a place in the large component of the System map. I think this is because Ellis' influence is spread across a range of topics, rather than focussed in a single area. In this data set, he is cited in papers that deal with lexical inferencing, negotiated meaning, words learners use in productive tasks, development of affix knowledge in L2 learners, vocabulary acquisition in classroom tasks and 
the effects of glossing on vocabulary uptake. Clearly, the clustering methodology used here puts Ellis at something of a disadvantage, and his role as a significant influence might have been different if we had allowed weaker links to be included in the map.

Sharwood Smith is cited in papers from two different spheres in the data set: word association and lexical errors. As with Ellis, this underestimates his importance in the earlier vocabulary research. It is also worth noting that Sharwood Smith was the founder editor of The Interlanguage Bulletin: Utrecht, a small journal which provided a friendly home for vocabulary researchers at a time when it was difficult to publish vocabulary research in the main applied linguistics journals.

Schouten-van Parreren's work is cited in this data set in papers that deal with lexical inferencing. This work, which is unusual in its citing of vocabulary research by Russian psychologists, should have been very influential, but it was largely ignored by English-speaking researchers at the time.

Sinclair is mostly cited in connection with the COBUILD corpus.

Of the three small clusters at the right-hand edge of the map, Kennedy and Sutarsyah co-authored with Nation a 1994 paper that dealt with the vocabulary of English for Academic Purposes (EAP); Gairns and Redman (1986) co-authored a series of vocabulary-focussed textbooks; Gass and Kellerman did not publish together, and this co-citation appears to be serendipitous.

For the rest, Gephi has identified five clusters in the data.

Cluster I, dominated by Hulstijn, and positioned at the south centre sector of the map, is the largest and the most disparate of the five clusters. The main theme of this cluster appears to be how learners acquire words, whether intentionally or incidentally, in a variety of input situations.

Cluster II, at the top of the map, and dominated by Paribakht and Wesche, seems to focus on reading in an L2, the strategies that learners adopt when they encounter unknown words and how small increments in word knowledge might be recorded.

Cluster III, positioned to the left of Cluster I, is dominated by Read. The main focus of this cluster seems to be formal vocabulary testing, with particular emphasis on vocabulary size and vocabulary richness. The sources in this cluster all make use of formal vocabulary tests.

Cluster $I V$, at the left hand edge of the map, consists mainly of frequency counts, but there is also a small subcluster of sources whose work is mainly concerned with the acquisition of L1 vocabulary from reading (Anderson, Nagy and Herman).

Finally, Cluster $V$, the small cluster at the Eastern edge of the map, consists of three psychologists whose work on the depth of processing (Craik and Lockhart) and mnemonics (Atkinson) has influenced L2 vocabulary research. This cluster also contains a number of sources whose main focus is multi-word sequences in L2. We might have expected Wray to be included in this cluster, but she actually appears in Cluster I. 
It is actually quite difficult to build a coherent account of the main themes found in the vocabulary research published in System. The main fault line seems to run between Clusters I and V that have a strong focus on word lists and corpora, on the one hand, and Clusters II and III, which have more of an emphasis on learners' performance, on the other hand. My personal interpretation of the map in Figure 3 is that it can best be seen as a set of core influences (Clusters I and III), and a set of peripheral ones (Clusters II, IV and V). The sources in the peripheral clusters seem to be older than the sources in the central clusters, and this might indicate that they are declining influences, rather than growing ones. Clusters II and IV are a bit worrying in this respect. Most of these influences published their main works in the 1980s and early 1990s, and there are surprisingly few co-citation links between these two clusters and the other clusters. Most of the members of Clusters II and IV have no co-citations with sources outside their own cluster. Cluster V is also largely disconnected from the rest of the graph - the main links here are with NC Ellis in Cluster I. There are no links between Cluster V and Clusters II, III and IV.

I think most readers of Vocabulary Learning and Instruction would agree that this characterisation of the research published in System accurately captures the main themes that we find in this data set. However, the map also has a number of characteristics that are thought-provoking in other ways.

The most striking feature of this map - one that is in stark contrast with some of the earlier maps that I have reported - is the very high level of interconnectedness between the five clusters. Normally, these bibliometric maps reveal clusters of influences that are quite discrete: the norm seems to be smaller clusters with strong connections between the members of a cluster, and only a few connections that range across the clusters. However, compartmentalisation is not a feature of the main System map, except perhaps in the case of Cluster V. (I suspect this may actually be an artefact caused by the way papers are selected for inclusion in the VARGA database.) Disregarding this anomaly, the level of connectedness between the clusters is fairly uniform.

A second feature of the map is that the clusters are fairly democratic, in that none of them is entirely dominated by a single source. Sometimes, in bibliometric maps, we find clusters that are star-shaped. A single source is co-cited with all the other members of the cluster, and it provides the only external links with the other clusters. This feature does not appear in Figure 3. Instead, many sources seem to be co-cited with many other sources, both within their own cluster and beyond it. One gets the impression that Figure 3 shows an unusually friendly research enterprise, where there is a high degree of awareness of what other people are doing in their research.

A third feature of the map is that most of the sources cited are active L2 vocabulary researchers. In contrast, the number of sources that influence the vocabulary research, while not actually doing L2 vocabulary research themselves, is relatively small, and for the most part, these cases appear in Clusters II and V, or among the disconnected sources beyond the eastern edge of the map. It is not clear to me whether this is a positive feature or not. One might argue that Figure 3 shows an intellectually mature field, which shares a common set of assumptions, 
and is generally confident about its own direction of travel. Alternatively, we might argue that the research reported in System could be described as somewhat self-referential: most of the sources who influence this work are themselves active L2 vocabulary researchers, who cite each other and rely on a small core of ideas that are largely taken for granted by everybody.

\section{Analysis 2: A longitudinal approach}

So far, we have treated the research published in System as a single body of work. In reality, of course, the priorities of vocabulary research have changed considerably over the 43-year period covered by the map. A recent paper by Lei and Liu (2019) used bibliometric methods to analyse the entire output of the journal in an analysis that used bibliometric features other than the co-citation method used here. Lei and Liu identified three main periods in the publication history of this journal: 1970-1989, 1990-2009 and 2010-2017. They argue that distinct themes can be identified in these time blocks, and they show how the major themes wax and wane over time. They argue, for example, that learner autonomy becomes significantly more frequent in the second period than it was in the first, but becomes less frequent as a topic of interest in the third period, and they interpret this as an indication of the growth and subsequent decline of this specific topic. Following Lei and Liu, it is also worthwhile for us to look at the L2 vocabulary research in smaller time slices, and the relevant data are provided in Figures 4-7. In the discussion that follows, I have divided the outputs in System into four small time slices, each covering a 10-year period.

The first period covers 1976-1987. The amount of vocabulary research published in the journal was small. Only 11 relevant papers appeared during this period (See Appendix 1). A total of 168 sources were cited in the data set, but only 13 sources were cited more than once. The pattern of co-citations among these 13 sources can be found in Figure 4. Gephi's analysis identifies three clusters in the data. In reality, there is very little structure in this map, and it only emerges if we accept the weakest of the co-citation links. The largest cluster at the south of the map, centred on Cohen, clearly identifies a group of sources working on imagery and vocabulary learning. The second cluster, at the northwest of the map, clearly identifies five sources concerned with guessing behaviour in L2 vocabulary learning. The third cluster to the north of the map identifies two sources who seem to have little in common. Corder is best known for his work on error analysis, which was a very influential theme in the research literature of the time; Goodman is an important source in the L1 reading literature. While the other two clusters are easily characterised, it is difficult to see how these two sources form a coherent cluster: their role in this map may just be a reflection of their overall importance in applied linguistics research at the time. This map also illustrates that we have a couple of relatively strongly connected clusters with only the weakest of links joining these clusters: take these very weak links away and we are left with three small isolated clusters and one disconnected source. The data suggest that there is a vocabulary research strand at this time, but it is only barely coherent as a field. It is also worth noting that of the sources identified in this map, only Paivio 


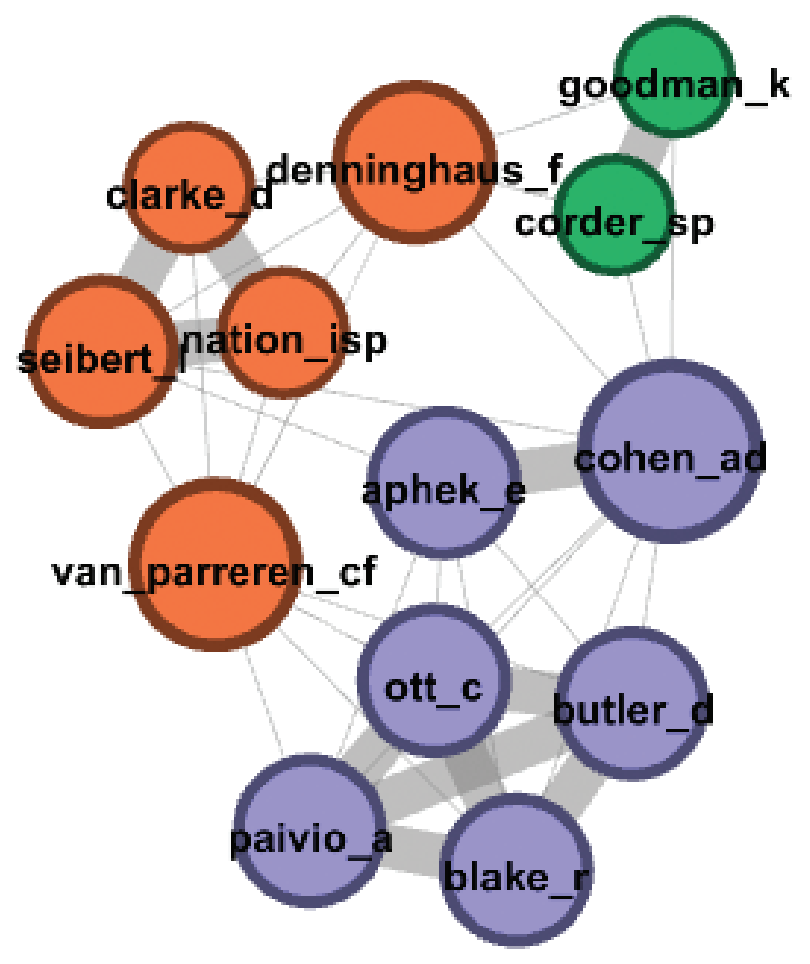

Figure 4. 1976-1987. The principal sources.

Data: 11 papers. Threshold for inclusion $=$ Two citations. Minimum co-citation strength $=$ One.

and Nation appear as significant influences in the larger map shown in Figure 3: Paivio as a minor disconnected influence, Nation as the central figure in the field. We will discuss Nation's role in more detail in the next section. For the moment, it is enough to note that it was relatively easy to become a significant influence in the 1976-1987 period: being cited only twice in 10 years was all you needed to be identified as a leading figure in vocabulary research, at least as far as System was concerned.

My second period covers 1988-1997. A total of 24 relevant papers were published in System during this period, more than double the number of relevant publications in our earlier period, and because of this inflation, it makes sense for us to raise the inclusion threshold for our map. Given 24 publications, an inclusion threshold of eight citations would be proportionately similar to the threshold that we used in the earlier map: to be included in the map, sources would need to be cited in about one-third of the papers in the data set. However, only one source (Nation) managed to cross this threshold. A total of 11 sources were cited at least four times in the 1988-1997 data set, and Gephi's analysis of the co-citation data for these 11 sources is shown in Figure 5.

What is really surprising here is that of the 11 sources who reach our more lenient inclusion threshold of four citations, only one source, Paul Nation, 


\section{sinclait $ـ$}

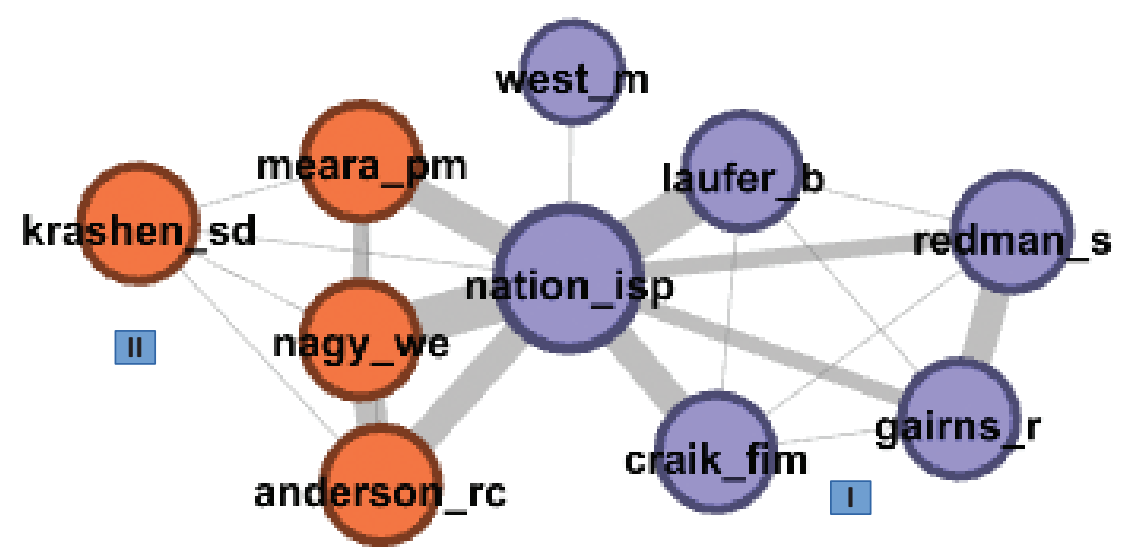

Figure 5. 1988-1997. The principal sources.

Data: 24 papers. Threshold for inclusion: Four citations. Minimum edge weight $=$ Two.

appears in both this analysis and in the previous one. The other 10 sources are new. This feels like a serious change in the field - not exactly a paradigm shift in the sense that Kuhn (1962) describes, but the sudden appearance of a set of coherent ideas about vocabulary that seems to be entirely lacking from the earlier work.

Gephi's analysis of the 1988-1997 data set identifies two clusters of sources and one detached source. The slightly larger group to the east of the map contains six sources. Nation is clearly the most significant influence in this map: he is co-cited with all the other sources except the detached source (Sinclair). Of the other sources in this cluster, Batia Laufer is best known at this point in time for her work on guessing behaviour in reading; Gairns and Redman, as we have already noted, published a series of influential textbooks that exploited some ideas developed by semantic theorists; Craik's work is mainly to do with the depth of processing; West is a word list. It is difficult to see what binds these sources into a coherent group other than the fact they are all strongly co-cited with Nation, and have no direct co-citations with the sources that make up the second cluster in the centre of the map. Most of the sources in this second cluster are concerned with reading - Nagy and Anderson deal mainly with L1 reading. Meara does not fit easily into this categorisation - he is cited mostly because of a review article (Meara, 1980), which seems to have become the go-to handy reference for vocabulary researchers in the early part of this period. Sinclair, the disconnected source, is mainly cited for his work on collocations and corpora by authors interested in dictionaries and their implications for L2 learners. Completely absent from this map is any reference to the imagery work or the lexical inferencing work that we 
identified in the 1976-1987 map, suggesting that these topics are declining in importance during this second period.

The third period that we can identify in the System data set is 1998-2007. Again, System included 24 relevant papers during this period, and again we would like to use a threshold of eight citations for inclusion in our map. In fact, only three sources are cited this often in the data: Nation is cited in 17 papers, Meara and Laufer are cited in 10. So once again, we are forced back onto a more lenient threshold for inclusion in the analysis. Fifteen sources were cited at least four times in these papers, a very slight increase compared to the two previous periods, and Figure 6 shows Gephi's analysis of these data.

Surprisingly, only six of the sources who were influential in the period 1988-1997 continue to be influential sources in this third period. Nation, Meara, Laufer, Krashen, Anderson and West all retain their significant influence status. Nation and Laufer continue as the most significant influences in this map: unusually, they are both co-cited with each of the other 13 sources.

Sinclair, Nagy, Craik, and Gairns and Redman continue to be cited, but are not cited often enough to reach the threshold for inclusion, and so do not figure in the new map. A surprisingly large majority of the sources are new: Thorndike and Lorge, Kennedy, Bauer, Schmitt, Read, Ellis, Hulstijn and Lewis.

Gephi finds three clusters in the data.

Cluster I, at the right-hand edge of the map, contains half of the continuing influences and three new ones. Lewis is author of two books dealing with the so-called lexical approach to language teaching. Krashen's work is concerned with reading in an L2 and how this promotes vocabulary learning. Laufer and Hulstijn are mostly cited for their work on how learners infer the meanings of unknown

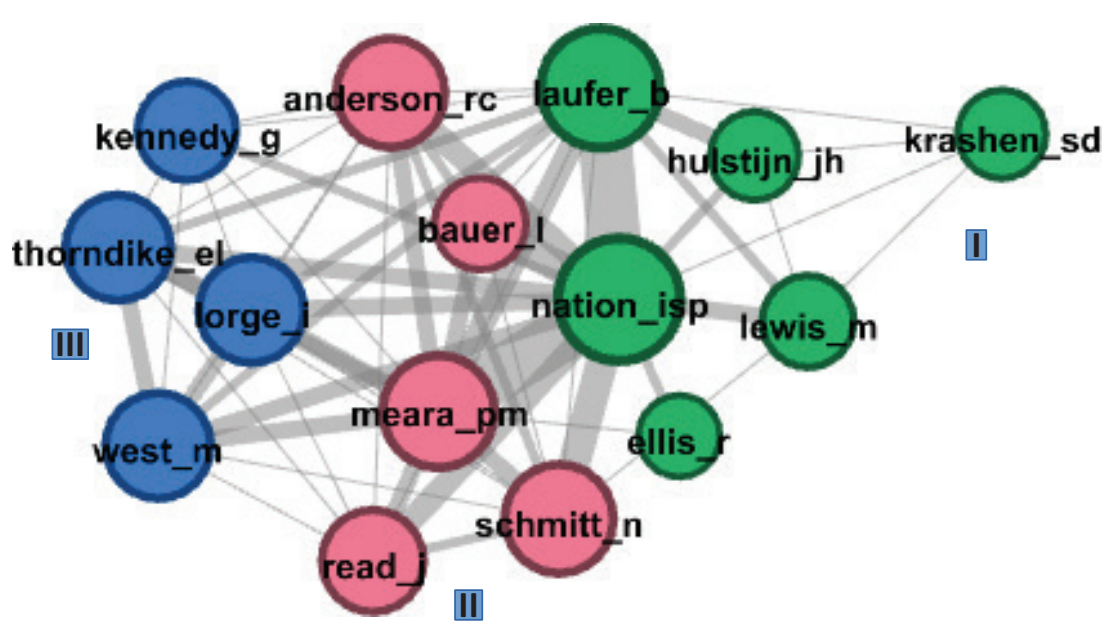

Figure 6. 1998-2007. The principal sources.

Data: 24 papers. Threshold for inclusion: Four citations. Minimum edge weight = Two. 
words in texts. Ellis is cited for his work on negotiated meanings. It looks, then, as though this cluster is mainly concerned with how learners use input to acquire new words. The distinguishing formal feature of this cluster is that all its members are co-cited with Krashen. While Krashen himself is not co-cited outside of this cluster.

Cluster II, in the centre of the map, contains three new sources, Bauer, Schmitt and Read. Bauer published with Nation an influential methodological paper that appeared 1983; this paper focussed on the idea of word families as units of vocabulary knowledge. Schmitt and Read both deal with aspects of vocabulary testing. This suggests that Cluster II is mostly concerned with assessing vocabulary knowledge, whereas Cluster I is more concerned with the circumstances under which learners acquire new words.

Cluster III, at the left hand edge of the map, looks like a set of word frequency counts, but the inclusion of Kennedy suggests that this cluster of influences is really about EAP, and the special word lists that EAP teaching requires.

Again, it is worth pointing out that the pattern of co-citations mapped in Figure 6 is surprisingly coherent, and it would be wrong to describe the three clusters as wholly distinct approaches to vocabulary acquisition. Each of the clusters has several members who are strongly co-cited with sources in the other clusters. Nonetheless, the map does suggest that some shifts are taking place in the way the field is structured. EAP has emerged as a new theme in this map: Michael West has been a continuing influence, but mainly in the context of evaluating reading material. The new EAP cluster seems to be taking these ideas in a new direction. The Laufer-Hulstjin cluster suggests that the role of unknown words in reading is emerging as a significant and specific research interest - indeed, both these authors collaborate on this topic in joint papers in other journals (Hulstijn \& Laufer, 2001; Laufer \& Hulstijn, 2001).

More importantly, perhaps, it is worth noting that there has been a subtle shift in the kinds of sources that appear in the map in Figure 6. For the first time, we can identify a cluster of sources based in New Zealand - Nation and Bauer, Read and R Ellis - and a second smaller group based in the United Kingdom (Meara and Schmitt). At the same time, we seem to be losing the "external" influences that we might expect to find in a map of this sort. Sinclair has gone vocabulary research in this period seems to be less interested in corpus linguistics. Craik has gone - vocabulary research in this period does not appear to be looking to psychology as a source of ideas. Anderson and Bauer are probably the only active sources in Figure 6 who would not self-identify as L2 vocabulary researchers. There is a suggestion here that as the research is becoming more coherent and more self-confident, it is also becoming more self-referential, and perhaps less open to new ideas.

This theme becomes even more apparent in the final period of the System data set, which covers 2008-2017. Vocabulary-related research mushroomed during this period, with a total of 52 relevant papers - almost half of the total vocabulary output in the journal. Forty of these papers - just short of $33 \%$ of the total vocabulary output - were published in the 5 years up to 2017. This is a phenomenal growth rate, suggesting that research outputs in L2 vocabulary acquisition are more than 
doubling every 5 years, following a long period of stability. It remains to be seen whether this is a sustainable feature for the long term. In the meantime, however, the 52 papers published between 2008 and 2017 provide us with a rich source of data to assess the current state of the art. The larger number of papers means that we can raise the inclusion threshold for the co-citation analysis, and this makes the analysis more reliable. Twenty-six sources in this data set are cited at least eight times (about 15\% of the papers), although some of the sources are cited much more than this: the most cited sources (Nation, Schmitt and Laufer, for instance, are cited in $88 \%, 79 \%$ and $73 \%$ of the papers, respectively). The overall pattern of co-citations among these 26 sources is shown in Figure 7.

With the minimum link strength set to eight, Gephi finds three clusters in the data. In reality, however, what we have here is one large cluster with a very high level of co-citation amongst the main sources. The average path length between any two sources selected at random is only 1.74 steps, mainly because Nation is co-cited with every other source, and there are only two sources who are co-cited with only one other source: West and Grabe are only co-cited with Nation. Schmitt, the second best connected source, is co-cited with all the members of the network except West, Grabe, Malvern and Richards. Laufer, the third best-connected source, is co-cited with all but five members of the network.

A striking feature of this map is the number of new sources it contains. Of the significant sources that appeared in the 1998-2007 map, Nation, Schmitt, Laufer, Hulstijn, Read, Meara and West survived into the 2008-2017 map, but they are joined by 20 new sources, that is, about two-thirds of the significant sources in Figure 7 are newcomers to the significant source list. The prominence of UK

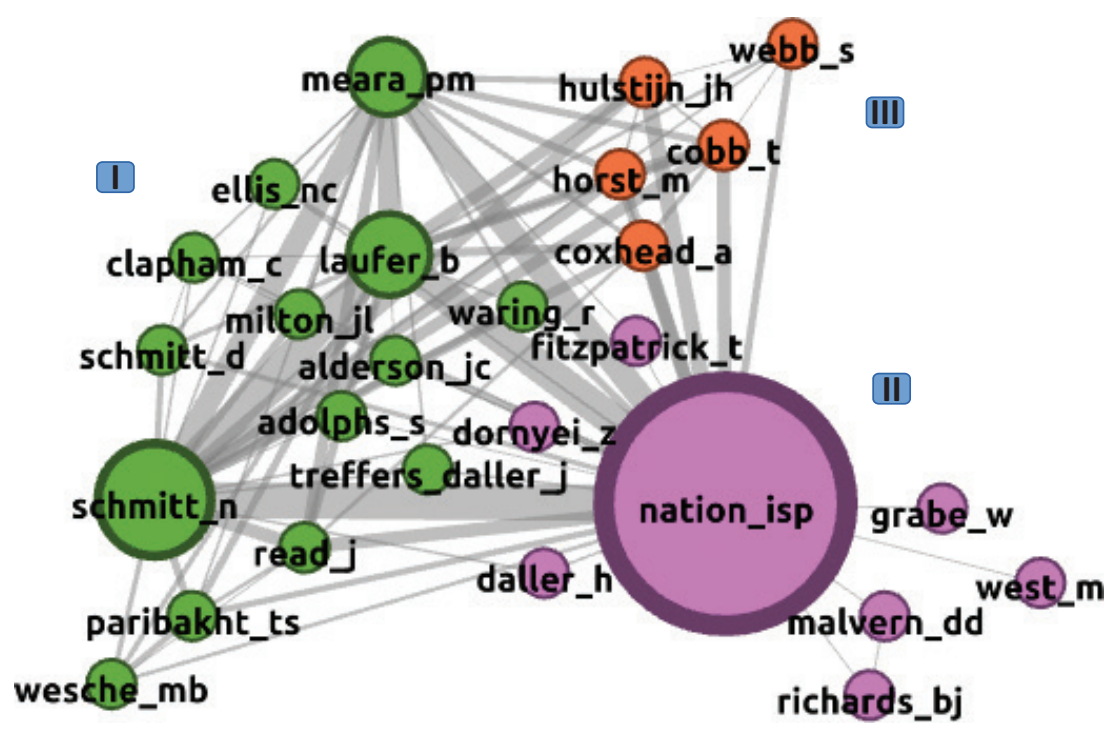

Figure 7. 2008-2017. The principal sources.

Data: 52 papers. Inclusion threshold = Eight citations. Minimum edge weight = Eight. 
researchers in this new list of arrivals will be obvious to most readers: Malvern, Daller, Treffers-Daller (and perhaps Milton) form a group of sources interested in lexical richness and formal measures of vocabulary use centred on Reading University. Schmitt is joined by Diane Schmitt, Adolphs and Dornyei - all with connections to Nottingham University - and Alderson and Clapham at Lancaster University. Meara's Swansea group has expanded with the appearance of Fitzpatrick, Horst and Waring. Taken together, these three groups numerically outweigh the New Zealand subcluster represented by Nation, Read, Coxhead and Webb. Ellis is an interesting new entry - a psychologist with interests in second language acquisition and bilingualism.

Formally, Gephi identifies three clusters in this data set, one large cluster and two smaller ones (see Figure 7).

Cluster I, the largest cluster in the 2008-2017 map, is the large cluster on the western edge of the map. This cluster contains 14 sources - just over half of all the sources found in this map. I think this cluster is mainly concerned with what could broadly be described as knowledge of words. Two main subclusters can be identified here: one deals with vocabulary size, another deals with vocabulary depth. Both subclusters are characterised by their concern with formal testing tools. The key source in this cluster is Schmitt, who works in both areas. Schmitt is co-cited with every other source in this cluster. Given the size of this cluster, it can probably be identified as the main cluster in present-day research, at least as we find it in System.

Cluster II, at the right hand edge of the map, dominated by Nation, is rather more difficult to describe succinctly. As we have already noted, every source in this map is co-cited with Nation, so it is perhaps a mistake to try to identify a single thematic focus for this cluster. Rather, what we have is a number of sources that are not strongly integrated into the rest of the network, but can be identified with themes that are not easily identified in the rest of the map. Grabe is an L2 reading source; West is the sole remaining source who deals explicitly with vocabulary selection and frequency lists; Malvern and Richards form a subcluster that deals with lexical richness, specifically a technical strand that uses Malvern's voc-d measure; Daller, also co-cited with Schmitt, should perhaps be seen as an outlier of the Malvern and Richards subcluster. Fitzpatrick, also co-cited with Meara, deals with productive vocabulary; Dornyei, also co-cited with Schmitt, deals with how learners approach the vocabulary learning problem. It is difficult to tell whether these subclusters are the ones that are likely to become more important in future research or less so. My guess is that formal measures of lexical richness may be on the decline, but that productive vocabulary may be an emerging focus that will become increasingly important in future.

Cluster III, the small cluster at the top of the map contains only five sources: Cobb, Horst, Coxhead, Hulstijn and Webb. The theme that links these sources seems to be what learners actually do when they are learning words. This cluster is basically a classroom vocabulary acquisition cluster, with a specific interest in learner behaviour.

Some of the clusters that we identified in Figure 6 have disappeared, notably the EAP group, the reading group (Krashen, Lewis and Anderson), as well as 
$\mathrm{R}$ Ellis and Bauer. What seems to be happening here is that the vocabulary research published in System is actually reflecting a narrower range of influences as it becomes larger. I am unsure if this is a good thing or not. On a larger scale, one might worry if the field as a whole was focussing on a narrower range of issues, and not challenging its own assumptions. However, it is possible that this narrowing of focus is merely a reflection of the way certain types of research tend to appear in particular journals. System, for instance, does not tend to attract papers that deal with the neurolinguistics.

\section{Discussion}

The title of this paper suggests that we might be able to discern in the vocabulary research published in System, the emergence of a vocabulary research paradigm. The idea of a paradigm first emerged in Kuhn's description of scientific revolutions (Kuhn,1970). In this work, Kuhn described a "paradigm shift" as "a reconstruction of the field from new fundamentals, a reconstruction that changes some of the field's most elementary theoretical generalizations, as well as many of its paradigm methods and applications" (pp. 84-85). Chomsky's reworking of the assumptions of linguistics is often cited as an archetypal example of a scientific revolution of this type (e.g., Percival, 1976; Searle, 1974). However, this description does not really apply to vocabulary research, simply because there was hardly any organised research of this type taking place in the 1960s and 1970s. Figure 8 shows the total vocabulary outputs identified in the VARGA database for this period (Meara, n.d.). The data suggest that over this entire period, only a handful of papers were published in any 1 year. Furthermore, the topics covered by this research vary hugely in their scope, and it is very difficult to find a coherent research agenda in this data set.

This means that the growth of vocabulary research after this period cannot really be interpreted as a scientific revolution. What may be relevant, however, is Kuhn's idea of a first paradigm: the product of a period of activity, during which researchers start to coalesce, gradually develop a research agenda on which they all agree and adopt a set of tools and methodologies that they are all happy with. I think that this idea seems to be what is showing up in the System data set:

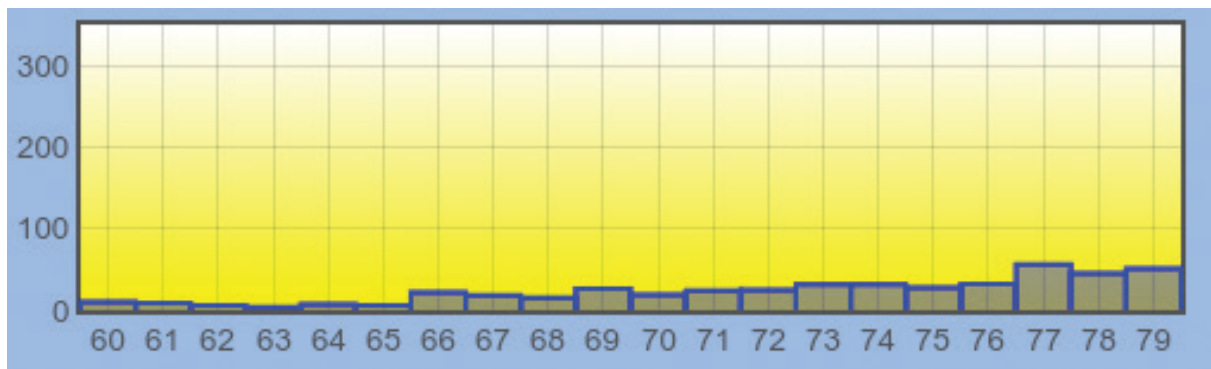

Figure 8. The number of vocabulary research papers published annually between 1960 and 1979.

Source: VARGA database (Meara, n.d.). Last updated on 28.07.19. 
the co-citation data in the 1976-1987 period shows a field that is fractured and incoherent, while the final co-citation data from the 2008-2017 period shows us a field that is highly integrated, sharing a common set of values, and heavily dependent on a single researcher that most people in the field would recognise as a "leader." The System data set suggests that the field gradually consolidates around a small core of very significant sources, with five influences (Nation, Laufer, Meara, Schmitt and Hulstijn) emerging as particularly important. Indeed, in the 2008-2017 data set, only three papers failed to cite any work by at least one of these five sources: Dolean (2014), Li and Chen (2016) and Tian and Hennebry (2016) - see Appendix 1. The grip of the first paradigm appears to be complete.

Figure 9 shows a different way of looking at this process. The figure plots the growing influence of the five principal sources over the years 1976-2017.

For all five main sources, the proportion of papers citing their work steadily increases across the System data set, with Nation cited in a massive $70 \%$ of the papers appearing in the 2008-2017 period. Interestingly, the growth lines are broadly parallel, suggesting that the relative influence of these five sources does not change much across the entire period. Schmitt is a particularly interesting case in that he

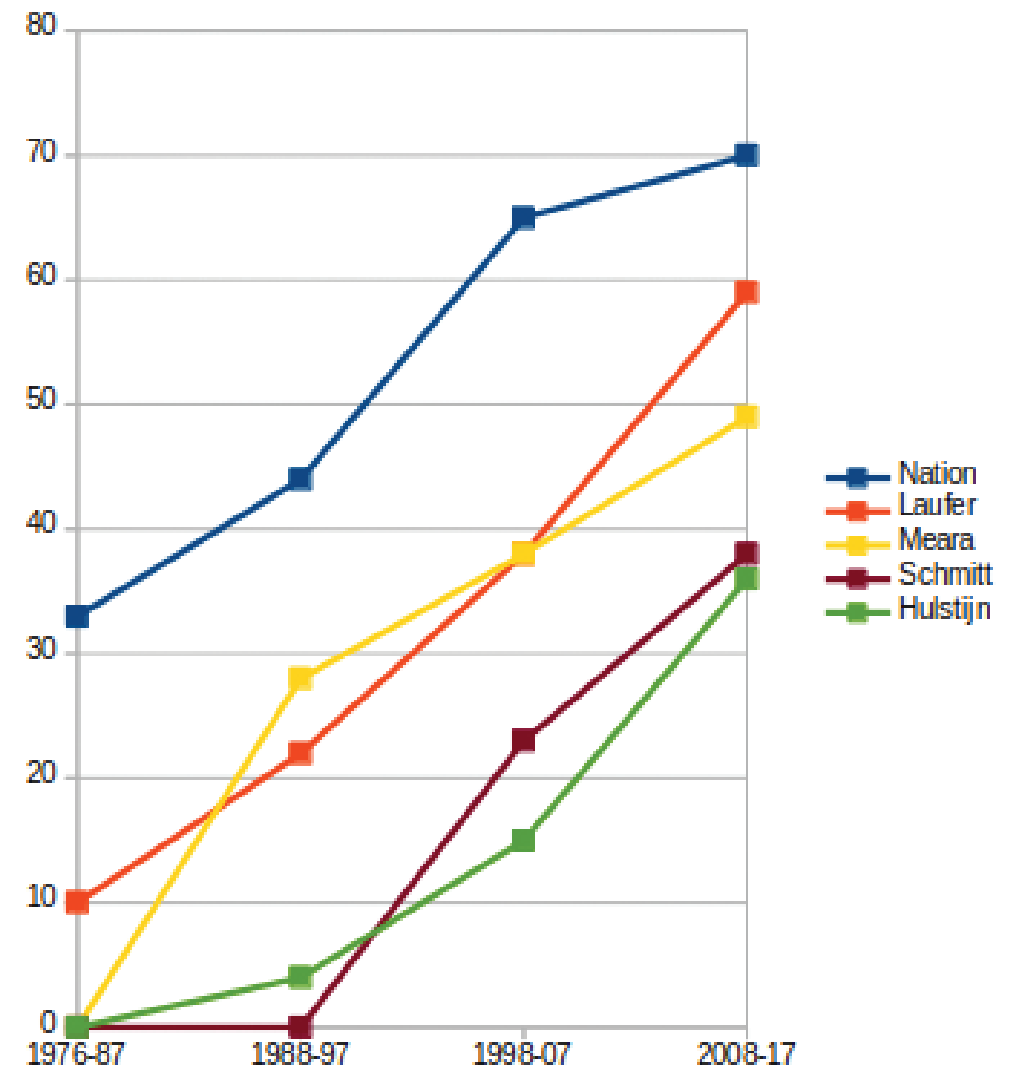

Figure 9: Percentage of papers citing Nation, Laufer, Meara Schmitt and Hulstijn in the System data set. 
does not appear in the chart until 1998, but rapidly becomes a significant influence after that date. (I intend to document Schmitt's rise to prominence in more detail in another paper.) To put the phenomenal growth figures in Figure 9 in some perspective, Figure 10 shows the proportion of papers citing the three leading figures from the 1976-1987 period. All three sources declined in influence from 1987, though the data for Cohen suggest that he retained some influence right through to 2017. 'These data echo the "waxing and waning" of topics reported in Lei and Liu (2019).

Of course, the establishment of a first paradigm does not mark the end of development. Two features in the data suggest that vocabulary research may not be quite as stable as the discussion so far has implied.

The first feature will be obvious to anyone who is familiar with the people who appear as sources in Figure 7. Most of these sources have already retired or are very close to retiring, and this means that their influence will inevitably decline. More than two-thirds of the sources that appear in Figure 7 fall into this category, perhaps hinting that the field might expect to experience a very large shift in the sources that it cites in the not too distant future. Of course,

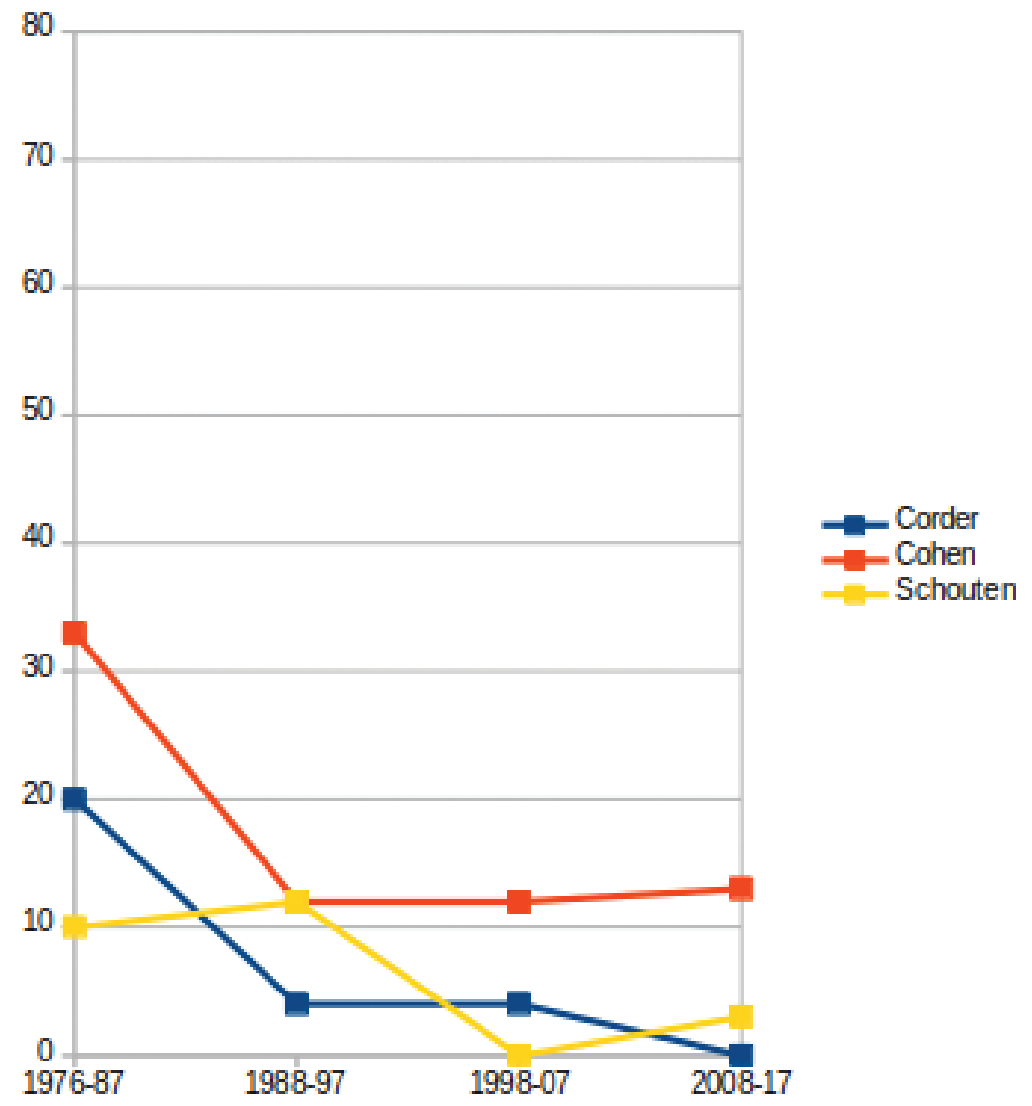

Figure 10: Percentage of papers citing Corder, Cohen and Schouten-van Parreren in the System data set. 
sources can continue to be influential for many years after their formal careers end. Textbooks tend to have a longer shelf life than individual papers, and some good examples of this genre play a significant role in the data sets examined here. It seems unlikely that classic texts such as Read (2000) or Nation (2013) will soon go out of fashion. In addition, some individual sources seem to be invulnerable to the ravages of time. Michael West, for instance, died in 1973 at the age of 85, after publishing his best work in the 1950s. Nonetheless, he still appears as a significant source in the full 1976-2007 data set (Figure 3), and in the most recent 2008-2017 map (Figure 7). However, most of us are unlikely to achieve this kind of lasting celebrity status, and that means that the list of most significant influences is likely to change in the years to come, as the current significant influences are replaced by new ones.

The second feature concerns the fact that our analysis so far has focussed on the 96 most cited sources in the System data set. I mentioned earlier that the threshold of six citations that we adopted to identify the 96 sources mapped in Figure 3 was essentially an arbitrary cut-off. Any cut-off of this sort has some negative consequences, and with our data, focussing our attention on the 96 most cited sources means that we have ignored a large number of less-cited sources. Specifically, in Figure 3 we have lost a large number of sources that were cited only four or five times in the data set. Bearing in mind that no-one was being cited very often in the 1970s and early 1980s, it is worth looking at this group of sources in more detail, as we might expect the next generation of significant sources to be found among this group. Ninety-nine sources in the System data set are cited four or five times - three more than the 96 sources who are mapped in Figure 3.

A complete list of these sources can be found in Table 3. Many of these names will be familiar to readers of $V L I$.

Figure 11 combines these 99 lesser cited sources into a co-citation map with properties that look very different from the maps that we have looked at so far. Gephi identifies a total of 10 clusters, with 14 detached sources that are linked to the rest of the network by only very weak co-citation links. Three of the clusters are detached from the main cluster group. I do not intend to analyse this map in

Table 3: Sources cited only four or five times in the system data set

\begin{tabular}{l}
\hline Sources cited five times \\
\hline aitchison_j biber_d bruton_a buxton_b conklin_k graham_s halter_r higa_m jarvis_s jiang_x \\
johansson_s johns_t jones_g keppel_g kim_y kintsch_w lightbown_pm muncie_j nesi_h \\
o'malley_jpellicer_sanchez_a peters_e rubin_j saragi_t schmidt_r schoonen_rsim_d stahl_s \\
stern_hh tinkham_t van_parreren_cf vandergrift_I vanderplank_rvidal_k wolter_b \\
\hline Sources cited four times \\
aizawa_k anthony_I aphek_e armstrong_c bachman_I barcroft_j beaton_a bell_h bogaards_p \\
bonk_w carroll_jb clarke_d collentine_j collins_I corder_sp de_bot_k engber_c engels_Ik erten_i \\
eyckmans_j fan_m flowerdew_j freebody_p fulcher_g greidanus_t guiraud_p harrington_m \\
hatch_e hirsh_d hyland_k jiang_n kiss_g koda_k koizumi_r leech_gn martinez_r mccrostie_j \\
meister_g milroy_r min_ht morris_I nurweni_a ortega_I pawley_a phillipson_r plass_j politzer_r \\
pressley_m raugh_m robinson_p sagarra_n scott_m segalowitz_ns seibert_I selinker_I simon_h \\
simpson_vlach_rr sonbul_s staehr_I swan_m takaki_m tidball_f truscott_j tulving_e
\end{tabular}




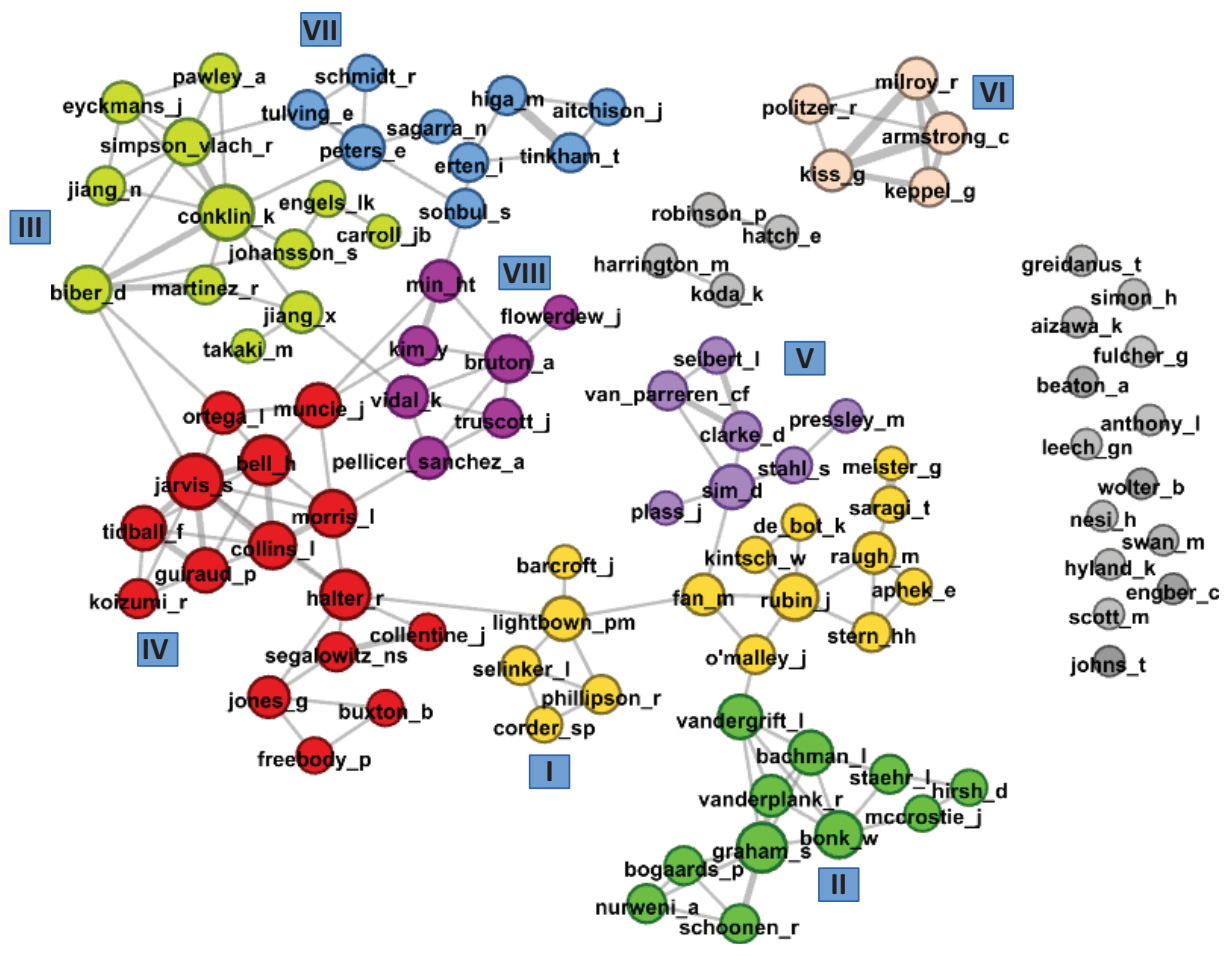

Figure 11. Co-citation map of 99 sources cited four or five times in the System data set. Edges with a weight of 1 removed in the interests of simplicity.

detail. Suffice it to say that we have a relatively large number of small clusters here, that the clusters are sparse rather than dense and that the clusters do not link strongly to other clusters: the clusters have some links with their immediately neighbouring clusters, but there are no co-citation links that reach across the entire network. The overall impression we get from this map is that there is a lot of ongoing activity, but this activity is not strongly co-ordinated.

The best analysis I can produce for this map is that the seven connected clusters focus on formulaic sequences, semantic effects on vocabulary acquisition, incidental vocabulary learning, guessing the meanings of unknown words, formal methods of vocabulary learning including mnemonics, learning words outside the classroom and productive vocabulary. As far as the detached clusters are concerned, the cluster of five sources at the northeast corner of the map is a set of sources with a particular interest in how word recognition is affected by script, and perhaps signal a genuinely new cluster.

One particularly interesting feature of this map is the small subcluster in the centre of the map that forms part of Cluster I. This subcluster plays a key role in preserving the integrity of the network. Without the Halter-Lightbown-Fan co-citations, the entire network would split into two components, with Clusters I, II and V largely made up of sources who were influential in the earlier periods under review, and Clusters III, IV, VII and VIII representing newer areas of enquiry. Most of the 
themes that we find in Figure 11 can also be identified in Figure 3, but two of the themes - the formulaic sequence theme (Conklin, Eyckmans, ...) and the learning words outside the classroom theme (Vanderplank, McCrostie, ...) look like strong areas of research which do not have a large presence in Figure 3. Given the rapid development of corpus technology at the current time, and the astonishing proliferation of vocabulary apps, I would expect to see these two clusters becoming much more prominent in the future. However, the productive vocabulary cluster (Jarvis, Segalowitz, Collins...) strikes me as one that is most likely to produce the most significant influences in future maps. The sources in this cluster are methodologically innovative and show a level of mathematical sophistication that is not always apparent in vocabulary research. This area is where I would expect to see the most interesting growth in the future.

\section{Conclusion}

This paper has provided a detailed bibliometric analysis of the vocabulary research that appeared in System between 1976 and 2017. To a large extent, this analysis was prompted by Lei and Liu's 2019 thoughtful report of the more general research trends that appeared in System over the same period. My analysis is narrower than Lei and Liu's work. It deals only with vocabulary research, and it uses a methodology that Lei and Liu do not apply to their much larger data set. Lei and Liu's paper does not specifically analyse the role of vocabulary research in System, and they do not single out vocabulary as a specially important part of the research published in System. However, Nation, Schmitt and Laufer all get a mention in their list of highly cited authors (p. 10), vocabulary learning is noted as an area of interest in "the teaching of specific skills" (p. 7) and Nation's Teaching and learning vocabulary (1990) and Learning a vocabulary in another language (2001/2013), and Read's Assessing vocabulary (2000) are listed among the most frequently cited references (p. 9). So Lei and Liu are aware of the vocabulary thread that appears in System, but their analysis does not capture what is going on in vocabulary research in any detail.

Clearly, these comments are not intended as a criticism of Lei and Liu. Their analysis of the System data set is concerned with much broader issues than the ones I have addressed. Nonetheless, I hope that the detailed analysis presented here has shown that it is a worthwhile exercise to shine the light of bibliometric methods, particularly co-citation analysis, onto small, highly focussed areas of research, where bibliometric methods have not traditionally been employed. Co-citation analysis seems capable of highlighting some subtle features of the way vocabulary research is reported in this journal.

My original intention in writing this paper was to try to capture the main trends of vocabulary research by looking in detail at the papers published in a single journal between 1976 and 2017, and in particular to argue that the vocabulary research in System shows some features of a first paradigm in development. The consolidation of a small core of sources that are cited by almost all the papers in the data set is a clear indication of an orthodoxy falling into place. My analysis has also hinted that this orthodoxy might be a temporary 
state of affairs that could be affected by some easily anticipated demographic changes. Of course, the analysis presented here covers only one journal, and the journal covered is one with a rather special focus, so it is not clear whether we can generalise from System to the field in general. More work on other journals is necessary. In the meantime, I hope that this paper will help to make readers of VLI more aware of some interesting features of the shifting landscape that is vocabulary research.

\section{Note}

1. I am grateful to John Read for pointing out that Cohen is very different from the other two cases mapped in Figure 10. He is the only one of the three to have published extensively since the 1990s, and remains an important source on vocabulary learning strategies. See, in particular, Cohen and Wang (2019).

\section{Acknowledgements}

I am very grateful to Julia Mitchell for her work in preparing the data set.

\section{References}

Baddeley, A. D., \& Hitch, G. (1974). Working memory. In G. H. Bower (Ed.), The Psychology of Learning and Motivation: Advances in Research and Theory (vol. 8, pp. 47-89). New York: Academic Press.

Bagster-Collins, E. W. (1918). A brief study showing the relation between the vocabulary and treatment of the annotated reading text. Modern Language Journal, 2(8), 341-351.

Bastian, M., Heymann, S., \& Jacomy, M. (2009). Gephi: An open source software for exploring and manipulating networks. International AAAI Conference on Weblogs and Social Media.

Cohen, A. D., \& Wang, I. K.-H. (2019). Fine-tuning word meanings through mobile app and online resources: A case study of strategy use by a hyperpolyglot. System, 85, 1-16.

de Solla Price, D. (1965). Networks of scientific papers. Science, 149(3683), 510-515.

de Solla Price, D., \& Beaver, D. (1966). Collaboration in an invisible college. American Psychologist, 21(11), 1011-1018.

Folse, K. (2004). Vocabulary Myths. Ann Arbor, MI: University of Michigan Press.

Gairns, R., \& Redman, S. (1986). Working with Words: A Guide to Teaching and Learning Vocabulary. Cambridge: Cambridge University Press.

Hulstijn, J., \& Laufer, B. (2001). Some empirical evidence for the involvement load hypothesis in vocabulary acquisition. Language Learning, 51(3), 539-558.

Kuhn, T. (1962/1971). The structure of scientific revolutions. Chicago, IL: University of Chicago Press. 
Laufer, B., \& Hulstijn, J. (2001). Incidental vocabulary acquisition in a second language: The construct of task induced involvement. Applied Linguistics, 22(1), 1-26.

Lei, L., \& Liu, D. (2019). The research trends and contributions of System's publications over the past four decades (1973-2017): A bibliometric analysis. System, 80, 1-13.

Lotka, A. J. (1926). The frequency distribution of scientific productivity. Journal of the Washington Academy of Sciences, 16(12), 317-324.

Meara, P. M. (1980). Vocabulary acquisition: A neglected aspect of language learning. Language Teaching and Linquistics: Abstracts, 13(4), 221-246.

Meara, P. M. (2014). Vocabulary research in The Modern Language Journal: A bibliometric analysis. Vocabulary Learning and Instruction, 3(2014), 1-28.

Meara, P. M. (2015). Vocabulary research in 1983: A bibliometric analysis. Linguistics Between and Within, 1(1), 187-198.

Meara, P. M. (2016). Two steps backwards: A bibliometric analysis of L2 vocabulary research in 1984. Linguistics Beyond and Within, 2(2016), $139-152$.

Meara, P. M. (2017). A new beginning? A bibliometric analysis of L2 vocabulary research in 1985. Linguistics Beyond and Within, 3(2017), 136-154.

Meara, P. M. (2018). Laying the foundations: A bibliometric analysis of L2 vocabulary research in 1982-86. Linguistics Beyond and Within, 4(2018), 108-128.

Meara, P. M. (nd). The Vocabulary Acquisition Research Group Archive. http:// www.lognostics.co.uk/varga/

Miller, G. A. (1956). The magical number seven, plus or minus two: Some limits on our capacity for processing information. Psychological Review, 63(2), 81-97.

Nation, I. S. P. (1990). Teaching and Learning Vocabulary. New York: Newbury House.

Nation, I. S. P. (2001/2013). Learning Vocabulary in Another Language. Cambridge: Cambridge University Press.

Paivio, A. (1971). Imagery and verbal processes. New York: Holt, Rinehart, and Winston.

Percival, W. K. (1976). The applicability of Kuhn's paradigms to the history of linguistics. Language, 52(2), 285-294.

Read, J. (2000). Assessing Vocabulary. Cambridge: Cambridge University Press.

Searle, J. (1974). Chomsky's revolution in linguistics. In G. Harman (Ed.), On Noam Chomsky: Critical Essays (pp. 2-33). Garden City, NJ: Anchor Books.

Small, H. (1973). Co-citation in the scientific literature: A new measure of the relationship between two documents. Journal of the American Society for Information Science, 24, 265-269. 
Sutarsyah, C., Nation, I. S. P., \& Kennedy, G. (1994). How useful is EAP vocabulary for ESP? A corpus based study. RELC Journal, 25(2), 34-50.

White, H. D., \& Griffith, B. C. (1981). Author co-citation: A literature measure of intellectual structure. Journal of the American Society for Information Science, 32, 163-171. 


\section{Appendix 1: The 115 vocabulary papers that were published in System between 1976 and 2017}

Abdullah, K. I., Puteh, F., Azizan, A.R., Hamdan, N., \& Saude, S. (2013). Validation of a controlled productive Vocabulary Levels Test below the 2000-word level. System, 41(2), 352-364.

Agustín Llach, M. P. (2010). Lexical gap-filling mechanisms in foreign language writing. System, 38(4), 529-538.

Akbarian, I. (2010). The relationship between vocabulary size and depth for ESP/ EAP learners. System, 38(3), 391-401.

Alavi, S. M., \& Akbarian, I. (2012). The role of vocabulary size in predicting performance on TOEFL reading item types. System, 40(3), 376-385.

Allan, R. (2016). Lexical bundles in graded readers: To what extent does language restriction affect lexical patterning? System, 59, 61-72.

Antes, T. A. (2014). Audio glossing during information-gap activities: The effect on learner output. System, 45, 163-174.

Bahns, J., \& Eldaw, M. (1993). Should we teach EFL students collocations? System, 21(1), 101-104.

Bao, G. (2015). Task type effects on English as a Foreign Language learners' acquisition of receptive and productive vocabulary knowledge. System, 53, 84-95.

Barker, D. (2007). A personalised approach to analysing 'cost' and 'benefit' in vocabulary selection. System, 35(4), 523-533.

Barrow, J., Nakanishi, Y., \& Ishino, H. (1999). Assessing Japanese college students' vocabulary knowledge with a self- checking familiarity survey. System, 27, 223-247.

Beheydt, L. (1987). The semantisation of vocabulary in foreign language learning. System, 15(1), 55-67.

Bestgen, Y. (2017). Beyond single-word measures: L2 writing assessment, lexical richness and formulaic competence. System, 69, 65-78.

Boers, F., \& Lindstromberg, S. (2005). Finding ways to make phrase-learning feasible: The mnemonic effect of alliteration. System, 33(2), 225-238.

Briggs, J. G. (2015). Out-of-class language contact and vocabulary gain in a study abroad context. System, 53, 129-140.

Broersma, M., \& Cutler, A. (2007). Phantom word activation in L2. System, 36, $22-34$.

Brown, D. (2013). Types of words identified as unknown by L2 learners when reading. System, 41(4), 1043-1055.

Bruton, A. (2007). Vocabulary learning from dictionary reference in collaborative translational writing. System, 35(3), 353-387.

Burling, R. (1983). A proposal for computer-assisted instruction in vocabulary. System, 11(2), 181-190. 
Chang, A. C. (2007). The impact of vocabulary preparation on L2 listening comprehension, confidence and strategy use. System, 35(4), 534-550.

Ching-Shyang Chang, A. (2007). The impact of vocabulary preparation on L2 listening comprehension, confidence and strategy use. System, 35(4), 534-550.

Chujo, S. D., \& Utiyama, M. (2006). Selecting level-specific specialised vocabulary using statistical measures. System, 34(2), 255-269.

Chun, D. M., \& Payne, J. S. (2004). What makes students click: Working memory and look-up behaviour. System, 32(4), 481-504.

Chung, T. M., \& Nation, I. S. P. (2004). Identifying technical vocabulary. System, 32, 251-263.

Clarke, W., \& Nation, I. S. P. (1980). Guessing the meanings of words from context: Strategy and techniques. System, 8, 211-220.

Cobb, T. (1997). Is there any measurable learning from hands-on concordancing? System, 25(3), 301-315.

Cohen, A., \& Aphek, E. (1980). Retention of second language vocabulary over time: Investigating the role of mnemonic associations. System, 8, 221-235.

Crossley, S. A., Cobb, T., \& McNamara, D. S. (2013). Comparing count-based and band-based indices of word frequency: Implications for active vocabulary research and pedagogical applications. System, 41(4), 965-981.

Cumming, G., Cropp, S., \& Sussex, R. (1994). On-line lexical resources for language learners: Assessment of some approaches to word definition. System, 22(3), 369-377.

Dolean, D. D. (2014). Using the keyword method in the classroom: Is the interacting imagery necessary? System, 45, 17-26.

Ellis, R., \& Heimbach, R. (1997). Bugs and birds: Children's acquisition of second language vocabulary through interaction. System, 25, 247-259.

Erten, I. H., \& Tekin, M. (2008). Effects on vocabulary acquisition of presenting new words in semantic sets versus semantically related sets. System, 36(3), $407-422$.

Eyckmans, J., Boers, F., \& Lindstromberg, S. (2016). The impact of imposing processing strategies on L2 learners' deliberate study of lexical phrases. System, $56,127-139$.

Flowerdew, L. (1993). Concordancing as a tool in course design. System, 21(2), 231-244.

Garnier, M., \& Schmitt, N. (2016). Picking up polysemous phrasal verbs: How many do learners know and what facilitates this knowledge? System, 59, 29-44.

Goh, C. (2000). A cognitive perspective on language learners' listening comprehension problems. System, 28, 55-75.

Hafiz, F. M., \& Tudor, I. (1990). Graded readers as an input medium in L2 learning. System, 18, 331-342. 
Haggan, M. (1991). Spelling errors in native Arabic-speaking English majors: A comparison between remedial students and fourth year students. System, 19(1-2), 45-61.

Hamada, M. (2009). Development of L2 word-meaning inference while reading. System, 37(3), 447-460.

Hamada, M., \& Koda, K. (2011). Similarity and difference in learning L2 word-form. System, 39(4), 500-509.

Harrington, M., \& Carey, M. (2009). The on-line Yes/No test as a placement tool. System, 37(4), 614-626.

Higginbotham, G. (2010). Individual learner profiles from word association tests: The effect of word frequency. System, 38(3), 379-390.

Higginbotham, G. (2013). Individual learner profiles from word association tests: The effect of word frequency. System, 38(3), 379-390.

Hirschel, R., \& Fritz, E. (2013). Learning vocabulary: CALL program versus vocabulary notebook. System, 42(3), 639-653.

Hu, H. C. M., \& Nassaji, H. (2014). Lexical inferencing strategies: The case of successful versus less successful inferencers. System, 45, 27-38.

Hu, H. M., \& Nassaji, H. (2016). Effective vocabulary learning tasks: Involvement Load Hypothesis versus Technique Feature Analysis. System, 56, 28-39.

Huang, L., \& Lin, C-C. (2014). Three approaches to glossing and their effects on vocabulary learning. System, 44, 127-136.

Ito, A. (2004). Two types of translations tests: Their reliability and validity. System, 32(3), 395-405.

Jiménez Catalán, R. M., \& Agustín Llach, M. P. (2017). CLIL or time? Lexical profiles of CLIL and non-CLIL EFL learners. System, 66, 87-99.

Johns, T. (1986). Micro-concord: A language learners' research tool. System, 14(2), $151-162$.

Juffs, A., \& Friedline, B. E. (2014). Sociocultural influences on the use of a web-based tool for learning English vocabulary. System, 42, 48-59.

Kaivanpanah, S., \& Alavi, M. (2008). The role of linguistic knowledge in word-meaning inferencing. System, 36(2), 172-195.

Kang, S.-H. (1995). The effects of a context-embedded approach to second language vocabulary learning. System, 23(1), 43-55.

Kasahara, K. (2011). The effect of known-and-unknown word combinations on intentional vocabulary learning. System, 39(4), 491-499.

Kelly, P. (1990). Guessing: No substitute for systematic learning of lexis. System, 18, 199-208.

Khezrlou, S., \& Ellis, R. (2017). Effects of computer-assisted glosses on EFL learners' vocabulary acquisition and reading comprehension in three learning conditions. System, 65(1), 104-116. 
Kim, H., \& Krashen, S. D. (1988). The author recognition and magazine recognition tests, and free voluntary reading as predictors of vocabulary development in English as a foreign language for Korean high school students. System, 26(4), 515-523.

Kim, J., Dewey, D. P., Baker-Smemoe, W., Ring, S., Westover, A., \& Eggett, D. L. (2015). L2 development during study abroad in China. System, 55, 123-133.

Koizumi, R., \& In'nami, Y. (2012). Effects of text length on lexical diversity measures: Using short texts with less than 200 tokens. System, 40(4), $554-564$.

Kojima, M., \& Yamashita, J. (2014). Reliability of lexical richness measures based on word lists in short second language productions. System, 42(1), 23-33.

Kubota, M. (2017). Post study abroad investigation of kanji knowledge in Japanese as a second language learners. System, 69, 143-152.

Kukulska-Hulme, A. (1988). A computerised interactive vocabulary development system for advanced learners. System, 16(2), 163-170.

Kwary, D. A. (2011). A hybrid method for determining technical vocabulary. System, 39(2), 175-185.

Laufer, B., \& Kimmel, M. (1997). Bilingualised dictionaries: How learners really use them. System, 25(3), 361-369.

Laufer, B., \& Osimo, H. (1991). Facilitating long-term retention of vocabulary: The second hand cloze. System, 19, 217-224.

Lee, S. (2003). ESL learners' vocabulary use in writing and the effects of explicit vocabulary instruction. System, 31, 537-561.

Leeke, P., \& Shaw, P. (2000). Learners' independent records of vocabulary. System, 28, 271-289.

Leffa, V. (1992). Making foreign language texts comprehensible for beginners: An experiment with an electronic glossary. System, 20(1), 63-73.

Leffa, V. J. (1998). Textual constraints in L2 lexical disambiugation. System, 26(2), 183-194.

Leontjev, D., Huhta, A., \& Mäntylä, K. (2016). Word derivational knowledge and writing proficiency: How do they link? System, 59, 73-89.

Li, H., \& Lorenzo-Dus, N. (2014). Investigating how vocabulary is assessed in a narrative task through raters' verbal protocols. System, 46, 1-13.

Li, Y., \& Qian, D. D. (2010). Profiling the Academic Word List (AWL) in a financial corpus. System, 38(3), 402-411.

Li, Y.-S., \& Chen, S.-H. (2016). Relative effectiveness of phonological and morphological awareness training on L2 word reading in EFL children. System, 60, 93-104.

Lin, L.-F. (2015). The impact of problem-based learning on Chinese-speaking elementary school students' English vocabulary learning and use. System, 55, 30-42. 
Macaro, E., \& Tian, L. (2015). Exploring teachers' oral explanation of new English lexical items in a Chinese university: Comparisons with dictionary information. System, 52, 78-90.

Matthews, J., \& Cheng, J. (2015). Recognition of high frequency words from speech as a predictor of L2 listening comprehension. System, 52, 1-13.

Meara, P. M., \& Fitzpatrick, T. (2000). Lex30: An improved method of assessing productive vocabulary in an L2. System, 28(1), 19-30.

Meara, P. M., Rodgers, C., \& Jacobs, G. (2000). Vocabulary and neural networks in the computational assessment of texts written by second language learners. System, 28, 345-354.

Mehrpour, S., \& Rahimi, M. (2010). The impact of general and specific vocabulary knowledge on reading and listening comprehension: A case of Iranian EFL learners. System, 38, 292-300.

Mochizuki, M., \& Aizawa, K. (2000). An affix acquisition order for EFL learners: An exploratory study. System, 28, 291-304.

Mondria, J.-A., \& Mondria-de Vries, S. (1994). Efficiently memorizing words with the help of word cards and 'hand computer': Theory and applications. System, 22(1), 47-54.

Montero Pérez, M., Van Den Noortgate, W., \& Desmet, P. (2013). Captioned video for L2 listening and vocabulary learning: A meta-analysis. System, 41(3), $720-739$.

Moran, C. (1991). Lexical inferencing in EFL reading course books: Some implications of research. System, 19(4), 381-400.

Morris, L., \& Cobb, T. (2004). Vocabulary profiles as predictors of the academic performance of TESL trainees. System, 32(1), 75-88.

Moulin, A. (1984). The problem of vocabulary teaching: An answer to Robbins Burling. System, 12(2), 147-149.

Muncie, J. (2002). Process writing and vocabulary development: Comparing lexical frequency profiles across drafts. System, 30(2), 225-235.

Nation, I. S. P. (1994). Review of four vocabulary course books. System, 22(2), 283-287.

Nation, I. S. P., \& Kyongho, H. (1995). Where would general service vocabulary stop and special purposes vocabulary begin? System, 23(1), 35-41.

Nesi, H., \& Meara, P. (1994). Patterns of misinterpretation in the productive use of EFL dictionary definitions. System, 22(1), 1-15.

Neufeld, S., Hancioglu, N., \& Eldridge, J. (2011). Beware the range in RANGE, and the academic in AWL. System, 39(4), 533-538.

Okamoto, M. (2015). Is corpus word frequency a good yardstick for selecting words to teach? Threshold levels for vocabulary selection? System, 51, 1-10.

Olsen, S. (1999). Errors and compensatory strategies: A study of grammar and vocabulary in texts written by Norwegian learners of English. System, 27(2), 191-206. 
Oxford, R. L., \& Scarcella, R. C. (1994). Second language vocabulary learning among adults: State of the art vocabulary instruction. System, 22, 231-243.

Palmberg, R. (1987). On lexical inferencing and the young foreign language learner. System, 15(1), 69-76.

Peters, E., Heynen, E., \& Puimège, E. (2016). Learning vocabulary through audiovisual input: The differential effect of L1 subtitles and captions. System, 63, 134-148.

Pickering, M. (1982). Context-free and context dependent vocabulary learning: An experiment. System, 10(1), 79-83.

Sagvall, A.-L., Brännström, B., \& Berghem, A. (1976). MIR: A computer based approach to the acquisition of Russian vocabulary in context. System, 4(2), $116-127$.

Saigh, K., \& Schmitt, N. (2012). Difficulties with vocabulary form: The case of Arabic ESL learners. System, 40, 24-36.

Sánchez, M. J. (2004). Effect of instruction with expert patters on the lexical learning of English as a foreign language. System, 32(1), 89-102.

Saragi, T., ISP Nation, \& Meister, G. F. (1978). Vocabulary learning and reading. System, 6(2), 72-78.

Schmitt, N. (1998). Quantifying word association responses: What is native-like? System, 26, 389-401.

Scholfield, P. J., \& Gitsaki, C. (1996). What is the advantage of private instruction? The example of English vocabulary learning in Greece. System, 24(1), $117-127$.

Sundqvist, P., \& Wikstrom, P. (2015). Out-of-school digital gameplay and in-school L2 English vocabulary outcomes. System, 51, 66-76.

Tanaka, M. (2017). Examining EFL vocabulary learning motivation in a demotivating learning environment. System, 65(1), 130-138.

Tegge, F. (2017). The lexical coverage of popular songs in English language teaching. System, 67, 87-98.

Tian, L., \& Hennebry, M. (2016). Chinese learners' perceptions towards teachers' language use in lexical explanations: A comparison between Chinese-only and English-only instructions. System, 63, 77-88.

Tinkham, T. N. (1993). The effect of semantic clustering on the learning of second language vocabulary. System, 21(3), 371-380.

Tracy-Ventura, N. (2017). Combining corpora and experimental data to investigate language learning during residence abroad: A study of lexical sophistication. System, 71, 35-45.

Tripp, S. D. (1990). The idea of a lexical meta-syllabus. System, 18(2), 209-220.

Vanderplank, R. (1990). Paying attention to the words: Practical and theoretical problems in watching television programmes with unilingual (CEEFAX) sub-titles. System, 18(2), 221-234. 
van Elsen, E., van Deun, K., \& Decoo, W. (1991). Word chip: The application of external versatility to an English lexical CALL program. System, 19(4), 401-417.

van Zeeland, H., \& Schmitt, N. (2013). Incidental vocabulary acquisition through L2 listening: A dimensions approach. System, 41, 609-624.

Wang, K.-H. (2015). The use of dialogic strategy clusters for vocabulary learning by Chinese students in the UK. System, 51, 51-64.

Wang, Y., \& Treffers-Daller, J. (2017). Explaining listening comprehension among L2 learners of English: The contribution of general language proficiency, vocabulary knowledge and metacognitive awareness. System, 65, 139-150.

Ward, J., \& Jungdaeng, C. (2009). Suffix knowledge: Acquisition and applications. System, 37(3), 461-469.

Waring, R. (1997). The negative effects of learning words in semantic sets: A replication. System, 25(2), 261-275.

Wilcox, A., \& A Medina. (2013). Effects of semantic and phonological clustering on L2 vocabulary acquisition among novice learners. System, 41, 1056-1069.

Wolter, B. (2002). Assessing proficiency through word associations: Is there still hope? System, 30, 315-329.

Xing, P., \& G Fulcher. (2007). Reliability assessment for two versions of the Vocabulary Levels Test. System, 35, 182-191.

Yamamoto, Y. (2014). Multidimensional vocabulary acquisition through deliberate vocabulary list learning. System, 42, 232-243.

Zareva, A. (2005). Models of lexical knowledge assessment of second language learners of English at higher levels of language proficiency. System, 33(4), $547-562$.

Zhao, T. (2015). Lexical processing and second language acquisition. System, 51, 95-97.

Zheng, Y. (2012). Exploring long term productive vocabulary development in an EFL context: The role of motivation. System, 40, 104-119.

Zheng, Y. (2016). The complex, dynamic development of L2 lexical use: A longitudinal study on Chinese learners of English. System, 56, 40-53. 